\title{
Preliminary study of software tracker usage to analyze inhibitory style on free fall movie events
}

\author{
Seni Susanti, Ea Cahya Septia Mahen*, and Ade Yeti Nuryantini \\ UIN Sunan Gunung Djati Bandung, Physics Education Department, Bandung, Indonesia
}

\begin{abstract}
This paper presents drag force analysis of free falling object using software tracker. We use video cupclips that have been embedded in this software. The video featured cupcakes to which hung a number of different paper clips were dropped simultaneously. We track the trajectory of free falling cupclips using the software to get the information of position, speed, and acceleration of each cupcake against time. From the data we get the value of drag forces and drag coefficients for each time. The result shows that the drag force value increased to almost constant value, otherwise the drag coefficient is reduced to almost constant values well. According to the results, the analyzed data has good agreement with the theory. Thus, software tracker can be used as media to learn drag force easily and inexpensively.
\end{abstract}

\section{Page layout}

Tracker is a software capable of analyzing and modeling motion phenomena, free of charge, and developed by Open Source Physics (OSP) using the Java framework $[1,2]$. Tracker has the ability to perform track (tracking) on the motion of an object so that it can obtain various information needed in the analysis on a motion event. Through the activity of recording a real motion phenomenon by using a video recorder. Tracker can be applied to various kinds of physics experiments based on mechanics. For example: straight motion [3], circular motion [4], rolling motion [5], parabolic motion [6], collision [1], law of conservation of mechanical energy [7], and free fall motion [8].

Free fall motion is the movement of objects under the influence of earth's gravitational force [9]. Any object that experiences a free fall accelerates downward. The coordinate axis used is the axis with the acceleration of earth's gravity (usually $\mathrm{g}=9.8 \mathrm{~m} / \mathrm{s} 2$ ). Free fall motion is an example of straight-line motion. Then all equations of uniform straight motion apply to free fall motion, with the acceleration value used is the acceleration of gravity.

However, when an object moves free in a fluid (water or air), it will work Drag Force against the motion of the object. The drag force depends on the shape of the object, the nature of the fluid, and the speed of the object relative to the fluid [9], [10]. In this paper we will report an early study of drag styles on free falling motion using the tracker software.

\section{Theory}

The equation of motion of free falling objects in the air follows the second law of the newton as follows:

$$
\begin{gathered}
\sum F_{y}=m \cdot \frac{d^{2} y}{d t^{2}} \\
m \cdot g-\rho g V-F_{d}=m \cdot \frac{d^{2} y}{d t^{2}}
\end{gathered}
$$

With $\mathrm{m}$ being the mass of an object, $\rho$ is the air density, $\mathrm{V}$ is the volume of air transferred. m.g is the gravity of the object, $\rho \mathrm{gV}$ is the bouyand style and $\mathrm{Fd}$ is the drag force of the object.

The drag force depends on the shape of the object, the nature of the fluid, and the speed of the object relative to the fluid. Objects that fall freely vertically in the air, will experience the fluid inhibition force (air). There are two types of resistance, namely, linear qasas resistances and quadratic case resistance. (Fowles). In the case of linear the drag force is proportional to the speed of the object whereas in the case of quadratic the inhibitory force value is proportional to the square of the speed of the object and is expressed in equation [11]:

$$
F_{D}=\frac{1}{2} \rho v^{2} C_{D} A
$$

With v being the object speed, CD is the coefficient of the object Drag and A is the cross-sectional area of the object

\section{Experimental Method}

In this experiment we used a tracker software to analyze drag styles. When the process of installing the Tracker software, video files and experiment tracker samples are selected to be included into the PC or download the video at https://physlets.org/tracker/download/mechanics_videos.

\footnotetext{
* Corresponding author: ea.cahya@uinsgd.ac.id
} 
zip [2] .Video used to be analyzed in this experiment is videos that have been embedded in the folder Tracker Cupclips.mov file that screenshot shown in Figure 1.

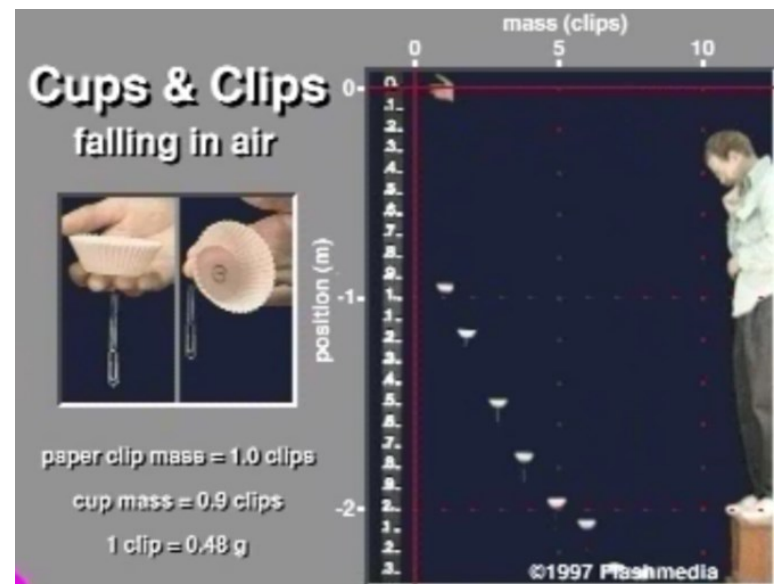

Fig. 1. Screenshoot of cupsclips.mov video.

Inside the video there is free falling motion eight pieces of paper cups hanging clip clips with different amounts from 1 to 8 . The mass of each clip is 0.48 grams and the cup mass is 0.43 grams. Each movement of the cups ditrack menggnakan tracker software so that the data obtained $\mathrm{y}$ positions, $\mathrm{y} v_{y}$ direction velocity, and direction velocity y $\mathrm{a}_{\mathrm{y}}$,

To Obtain the drag force of each free fall event each cup cake we use 2 Newton's Law ignores the boyand style because the volume of air transferred is very small, that is:

$$
\begin{gathered}
\sum F=m a \\
F_{D}-F_{g}=m a \\
F_{D}=m(a+g)
\end{gathered}
$$

\section{Result and Discussion}

Figure 2 shows the track results of several free fall events from cupcake with different masses. At the same time we see different track results for each fall free movement.

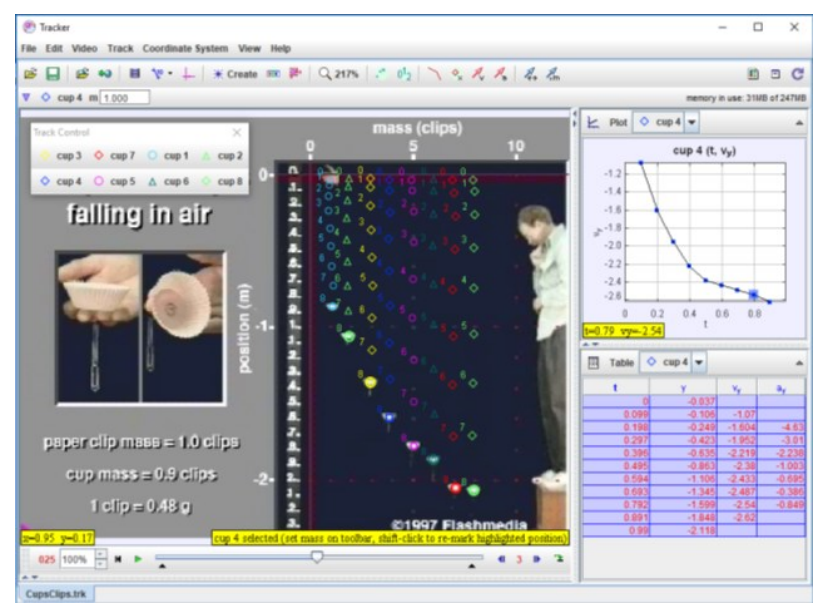

Fig. 2. Tracking of cupclips motion.
The velocity vs. time curve is shown in Figure 3. From the figure it is seen that the time taken to arrive at the same position of each cupcake with different masses requires different times. Cupcake with the smallest mass requires a relatively longer time to get down than the cupcake with a larger mass. This shows that the acceleration experienced by each cupcake is also different. So as to cause the speed of each time experienced by the object is also different.

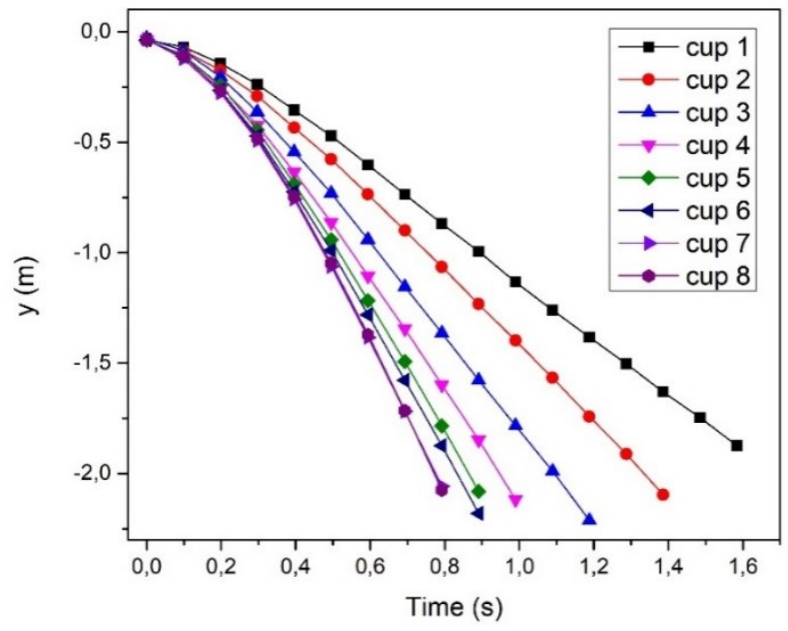

Fig. 3. Curve of position versus time.

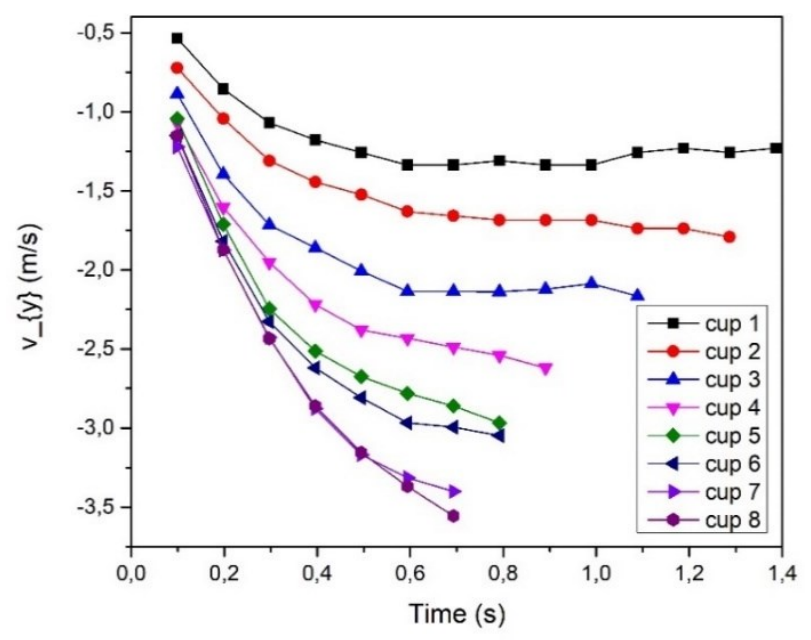

Fig. 4. Curve of velocity versus time.

The speed for each cupcake is shown in Figure 4. From the figure it appears that the speed for each cupcake has increased but the longer it goes to a constant value. This occurs because there is an air drag force that causes the speed at which the free fall event becomes constant or is called terminal density. This happens when the gravity of an object is offset by its inhibitory force. So when the gravity of the object has been offset by the drag force it will cause the acceleration of the object to zero. This we can see in the acceleration curve in Figure 5. From Figure 5 we can see the acceleration of each cupcake with different mass shrinking to zero. 


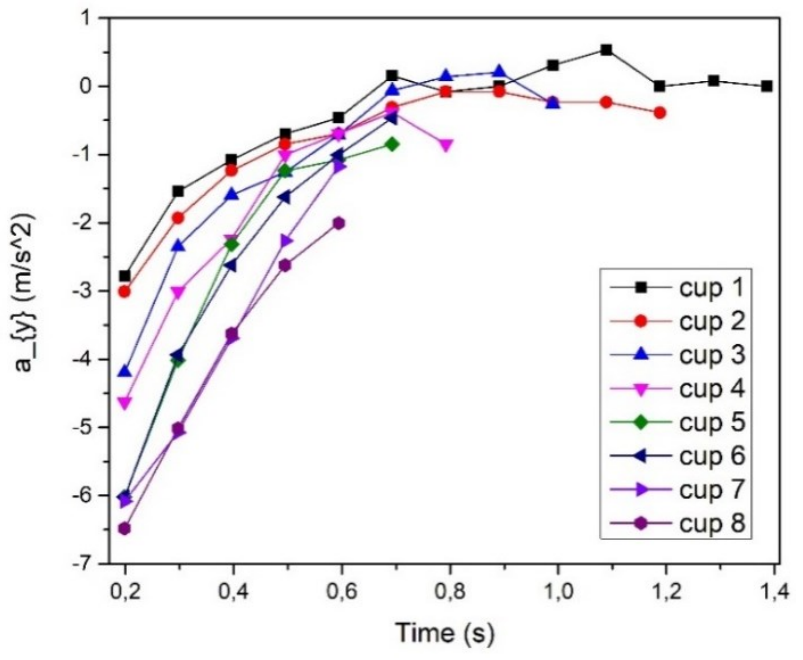

Fig. 5. Curve of acceleration versus time.

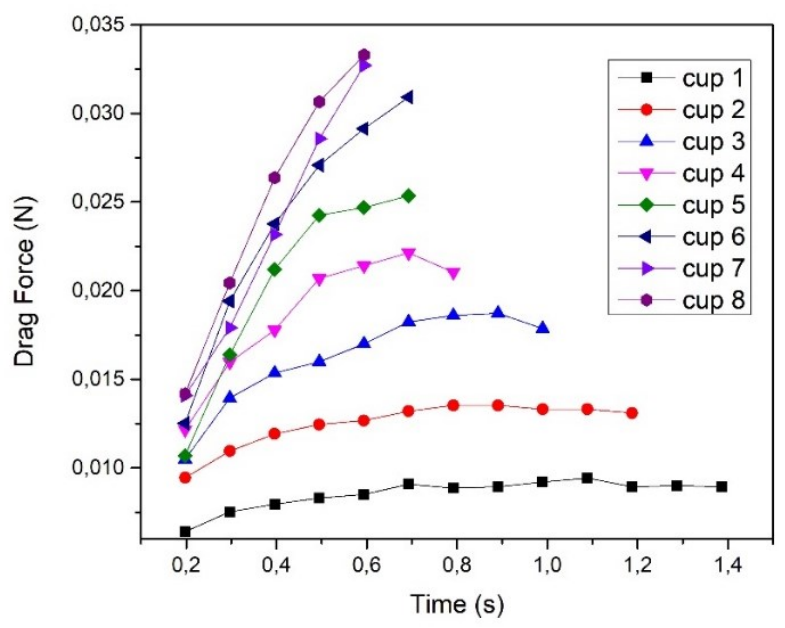

Fig. 6. Curve of drag forces versus time.

Figure 6 shows the drag curves experienced by each cupcake. Seen from the curve the drag force on each cupcake is enlarged with time. This corresponds to the theory that the value of the resistor depends on the square of the speed. The faster the object moves the greater the value of the inhibitory force. The value of drag will be constant when its speed is also constant. This happens because the drag force has offset the gravity. We compare the value of the drag force with a constant value with the gravity value of cup 1 to cup 3 presented in Table 1. The cup 4 to cup 8 has not reached a constant drag value. From Table 1 we can see that the value of Gaya weight is almost equal to the value of drag force whose value has been relatively constant.

Table 1. Comparison of gravity of objects with a drag force when it reaches a constant value.

\begin{tabular}{|c|c|c|c|l|}
\hline Cup & $\begin{array}{c}\text { Mass } \\
(\mathrm{Kg})\end{array}$ & $\begin{array}{c}\text { Gravity } \\
(\mathrm{N})\end{array}$ & $\begin{array}{c}\text { Constant } \\
\text { drag force } \\
(\mathrm{N})\end{array}$ & Difference \\
\hline Cup 1 & 0,00091 & 0,008918 & 0,008992 & $7,43 \mathrm{E}-05$ \\
\hline Cup 2 & 0,00139 & 0,013622 & 0,013427 & $-0,0002$ \\
\hline Cup 3 & 0,00187 & 0,018326 & 0,018524 & 0,000198 \\
\hline
\end{tabular}

\section{Conclusion}

We have successfully used the tracker software to analyze drag styles on free fall events. The results show that objects with different masses experience different accelerations as well. This is due to the inhibitory force experienced by each different object. The object will have terminal speed when the weight of the object has been offset by its drag force. So to learn the style of resistor easily and cheaply can use Tracker software.

This work was support by a research grant (2017) from UIN SunanGunungDjati Bandung and the Ministry of Religious Affairs, Republic of Indonesia.

\section{References}

1. D. Brown and A. J. Cox, Innovative Uses of Video Analysis, Phys. Teach., vol. 47, no. 2009, p. 145, (2009)

2. D. Brown, Tracker Video Analysis and Modeling Tool, Open Source Physics, [Online]. Available: http://www.opensourcephysics.org/items/detail.cfm ?ID=7365. [Accessed: 01-Jan-2017]. (2017)

3. L. K. Wee and T. K. Leong, Video Analysis and Modeling Performance Task to Promote Becoming Like Scientists in Classrooms, Am. J. Educ. Res., vol. 3, no. 2, pp. 197-207, (2015)

4. J. Kinchin, Tracker demonstrates circular motion, Phys. Educ., vol. 47, no. 1, pp. 15-17, (2012)

5. E. C. Prima, M. Mawaddah, N. Winarno, and W. Sriwulan, Kinematics investigations of cylinders rolling down a ramp using tracker, AIP Conf. Proc., vol. 1708, no. February 2016, (2016)

6. L. K. Wee, C. Chew, G. H. Goh, S. Tan, and T. L. Lee, Using tracker as a pedagogical tool for understanding projectile motion, Phys. Educ., vol. 47, no. 4, pp. 448-455, (2012)

7. J. Bryan, Video Analysis Software and the Investigation of the Conservation of Mechanical Energy, Contemp. Issues Technol. Teach. Educ., vol. 4, no. 3, pp. 284-298, (2004)

8. L. K. Wee, K. K. Tan, T. K. Leong, and C. Tan, Using Tracker to Understand 'Toss Up' and Free Fall Motion: A Case Study, Phys. Educ., vol. 50, no. 4, pp. 436-442, (2015)

9. D. Horvat and R. Jecmenica, The free fall experiment, Resonance, vol. 21, no. 3, pp. 259275, Mar. (2016)

10. G. R. Fowles, Analytical mechanis. (Philadelphia: Saunders Collage Publishing, 1986)

11. J. P. Owen and W. S. Ryu, The effects of linear and quadratic drag on falling spheres: An undergraduate laboratory, Eur. J. Phys., vol. 26, no. 6, pp. 1085-1091, (2005) 